used measures of the maximum thicknesses, I have considered that these would in all probability not differ much from the original average thicknesses of the same rocks before they had suffered denudation. No doubt some rocks may have been wholly destroyed by denudation, or are so covered up by later deposits as to be beyond our reach, and to allow for these $I$ am willing to admit that my estimate of the whole thickness of the rocks, and therefore of the time taken to produce them, may have to be considerably increased; but this would bring my figures nearer to those usually arrived at, not enormously further from them as Mr. Reade endeavours to prove.

Yet again, Mr. Reade points out that continents have fluctuated, and have sometimes been larger than now. To allow for this he doubles the land surface and reduces the corresponding thickness of the strata to one-half! But, surely, if the continents have been sometimes larger, they have also been sometimes smaller, and I see no reason to think we can take any fairer average than that of the present area; and even if the average $h a d$ been double, then the denudation and the deposit would presumably have been double also, not half as Mr. Reade suggests.

With regard to my fundamental position-that the areas of deposition are (and always have been) very much smaller than the areas of denudation, and that, in making any estimate of geological time founded on the thickness of the sedimentary rocks and the known rate of denudation, this fact must be taken account of, Mr. Reade makes no objection; and, whatever "confusion of ideas" may have pervaded my estimate, the subject has certainly not been rendered clearer by his criticism.

Finally, as regards the general theory of the "Permanence of Oceans and Continents" (or, more properly, of Oceanic and Continental areas), which Mr. Reade somewhat sneeringly remarks "is now becoming fashionable,"-it is time that its opponents should give up petty criticism of unimportant details or collateral issues, which have little bearing on the main question, and attempt to grapple with the whole body of facts and arguments adduced in its support by some of the first geologists of the day, and which I have endeavoured to set forth in a connected form in the pages of "Island Life." Any such general examination of the question from an adverse point of view, I have hitherto failed to meet with.

Alfred R. Wallace.

\title{
THE OLD HYTHE PINNACLE OF CHALK.
}

Sin,-On referring to the Life of Lyell, I find the letter relating to the disappearance of the Old Hythe Pinnacle of Chalk was written in 1869 , not 1864 . The evidence of Lyell does not therefore conflict with that of Prof. Seeley and Mr. Searles Wood, as I thought it did, but taken with theirs, rather points to the total destruction of the pinnacle between those dates. With this correction I must close the correspondence on this subject so far as I am concerned.

Sept. 4, 1883.

T. Mellakd Reade. 